\title{
Metastatic cancer of the pancreas: Historical review
}

\section{Onuigbo WIB*}

\author{
Medical Foundation and Clinic, 8 Nsukka Lane, Enugu, Nigeria
}

${ }^{*}$ Corresponding author: Onuigbo WIB, Medical Foundation and Clinic, 8 Nsukka Lane, Enugu 400001, Nigeria, E-mail: wilson.onuigbo@gmail.com

Citation: Onuigbo WIB (2014) Metastatic cancer of the pancreas: Historical review. J Cancer Sci Clin Oncol 1(1): 104. doi: 10.15744/2394-6520.1.104

Received Date: September 22, 2014 Accepted Date: December 03, 2014 Published Date: December 05, 2014

Abstract
During the $19^{\text {th }}$ Century, there was a difficult choice concerning whether a pancreatic cancer is primary or secondary. However, in
this paper, it is shown that some views were decidedly in favor of attack from other primaries. Indeed, the evidence of spread to the
pancreas included either concise or coalescent lesions.

\section{Introduction}

On reviewing my collection of the $19^{\text {th }}$ Century literature on metastatic pancreas cancer, there was a surprising agreement in the presentations by noted authorities. Thus, Wilks and Moxon [1] in 1875 wrote, "It is often impossible to say whether the disease began in the pancreas or in the glands about its head," while Richard Bright [2] was perplexed that in his 8th case, "it was almost impossible to say which was pancreas and which was absorbent," i.e., lymph node. In the above statements, I have introduced italics in order to highlight the closeness of the conceptions. It is necessary to realize that, by the end of the century, Neve [3] was able to declare that "The surface of the pancreas was involved in a mass of new growth, which, however, was separated from the glandular structure by a thick band of fibrous tissue."

\section{Historical texts}

Recently, the question of the eponym, the Virchow-Troisier node, was taken up by Morgenstern [4]. It was to the effect that Virchow in 1848 and Troisier in 1886, in Germany and France respectively, noted the significance of palpable neck nodes in the presence of intraabdominal malignancy. Indeed, Bartholow [5] by 1880 wrote concerning pancreatic cancer thus: "If enlarged glands be felt, and especially if the cervical lymphatics are enlarged, support will be given to the supposition that an existing tumor is malignant."

In 1876, Bristowe [6] took a wide view thus:

The pancreas is not unfrequently the seat of such formations; but they are rarely, if ever, of primary origin within it; they are sometimes a consequence of the generalization of malignant tumours, but are much more frequently due to extension of disease from the stomach, retro-peritoneal glands, or peritoneum. However, in the case of the pyloric extremity of the stomach that the pancreas most frequently becomes involved.

A decade later, Starr [7] was discursive as follows:

Secondary carcinoma of the pancreas usually first appears in, and is limited to, the head of the gland. It seldom occurs in isolated nodules, but the growth is generally continuous with the primary cancerous mass ... The primary growth is almost uniformly situated in the stomach, duodenum, liver, or gall-bladder, though occasionally it may be seated in some distant organ; in such cases the pancreatic tumor appears as an isolated nodular mass.

Much earlier, in 1838, Hall [8] was apologetic in his overview. He hesitated thus: "It may be scirrhous, or compressed by scirrhous; but the symptoms are unknown, and to this day, the diseases of the pancreas are of as little moment in a therapeutic point of view, as they are rare in their occurrence."

With special reference to the pancreas, a major point of interest centered on whether growths "developed around it, or in the intervals of its locules" [9]. In the words of Wilks, [1] "it is remarkable how the pancreas escapes even where cancer exists around it." In fact, as he elaborated, "in cancer of the stomach, this organ may be dissected off, together with the diseased lymphatic glands, and be found quite untouched; this is the rule, and cancer in the pancreas the exception." As he continued, "sometimes, however, it may be affected by contact, and more rarely, separate deposits of cancer are found within it."

Although "metastasis" was known by 1819, [10] the attractive concept was still that of "extension" rather than "metastasis" [11,12]. However, Coats [13] was correctly observant in respect of both the number and the location thus: "There were also numerous tumours in the pancreas, which were greatly enlarged, especially the tail part." Similarly, exactitude was manifested by Packard and Steele [14] in their 1897 case report of lung cancer presenting with Addison's disease in that they listed the pancreas among the colonized organs. 
Comparison came nicely into the picture, seeing that Walshe [15] was watchful. Thus, as he observed, "while I find numerous cases in which the disease has spread from the pancreas to the duodenum, omentum, mesentery, liver, and even the supra-renal capsules and kidneys, I cannot feel satisfied that the propagation has in any case of really cancerous affection of the pancreas certainly taken place in the converse direction." Apparently, he found only a French example dating to 1830.

\section{Discussion}

The above published materials speak in favor of not only metastasis to the pancreas but also of metastasis from it. In this context, when the growth is situated in one part of the pancreas, since my contention is that distance is an element of metastasis, any other deposits in it are not truly metastatic [16].

From the Mayo Clinic, Malagelada [17] reminisced that "pancreatic cancer remains a challenge to researchers and investigators alike." Thus, regarding all the important imaging techniques, it is salutary that "This process has been accelerated by continuing technical improvement to enhance the quality of the images obtained".

Of some interest is that in a Swedish community, some patients were registered with the National Cancer Registry as having pancreatic cancer but this diagnosis was shown at autopsy to be wrong [18]. In terms of better diagnosis, a recent study [19] showed how regard was paid successfully by way of fine-needle aspiration cytology and immunocytochemistry. Another good example was given in which metastatic work-ups included the use of preoperative positron emission tomographic scans [20].

In conclusion, the good news is that the probability is that, if the pancreas can be identified as the only site of spread, radical resection may prolong survival [21].

\section{References}

1. Wilks S, Moxon W (1875) Lectures on Pathological Anatomy (2 $\left.{ }^{\text {nd }} E d n\right)$ Lindsay and Blakiston publishers, London.

2. Bright R (1833) Cases and observations connected with disease of the pancreas and duodenum. Med Chir Trans 18: 1-56.

3. Neve ET (1891) On the morbid anatomy of the pancreas. Lancet 138: 659-61.

4. Morgenstern L (1979) The Virchow-Troisier node: a historical note. Am J Surg 138: 703.

5. Bartholow R (1880) A treatise on the practice of medicine. Lond: Lewis 139.

6. Bristowe JS (1876) A treatise on the theory and practice of medicine, ( $3^{\text {rd }}$ Edn) Lond: Smith, Elder \& Co Publishers, USA.

7. Pepper W, Starr L (1885) Diseases of the pancreas A System of Practical Medicine Vol II, USA.

8. Hall M (1836) Lectures on the theory and practice of medicine. Lancet 30: 673-8.

9. Lawrence W (1831) History of a case in which, on examination after death, the pancreas was found in a state of active inflammation. Med Chir Trans 16: 367-76.

10. Rees A (1819) The Cyclopaedia; or, Universal Dictionary of Arts, Science, and Literature Longman, Hurst, Rees, Orme \& Brown publishers, London.

11. Orth J (1877) A compend of diagnosis in pathological anatomy with Directions for Making Post-mortem Examinations, Houghton publishers, USA.

12. Stengel A (1899) A text-book of pathology ( $2^{\text {nd }}$ edn), Saunders publishers, USA.

13. Coats J (1885) Catalogue of the Pathological Museum of the Western Infirmary Glasgow, Alex Macdougall publishers.

14. Packard FA, Steele JD (1897) A case of sarcoma of the lung, with symptoms of Addison's disease from involvement of the suprarenal capsules. Med News 71: 329-33.

15. Walshe WH (1846) The nature and treatment of cancer, Taylor and Walton publishers, London.

16. Onuigbo WIB (1966) Lung cancer metastasis to the pancreas and its surrounding lymph nodes. Br J Dis Chest 60: 152-5.

17. Malagelada JR (1979) Pancreatic cancer: an overview of epidemiology, clinical presentation, and diagnosis. Mayo Clin Proc 54: 459-67.

18. Tarpila E, Borch K, Kullman E, Liebery G (1986) Pancreatic cancer. Ann Chir Gynaecol 75: 146-50.

19. Das DK, Mugim AT, Haji BI, AL-Bishi K, Abdulghani R (2011) Pancreatic metastasis in a case of small cell lung carcinoma: Diagnostic role of fine-needle aspiration cytology and immunocytochemistry. J Cytol 28: 226-9.

20. Golbin JM, Kaira S, Midthun DE (2006) Metastatic cancer to the pancreas. J Thorac Oncol 1: 360-1.

21. Wente MN, Bergman F, Frohlich BE, Schirmacher P, Buchler MW, et al. (2004) Pancreatic metastasis from gastric carcinoma: a case report. World J Surg Oncol 2: 43 .

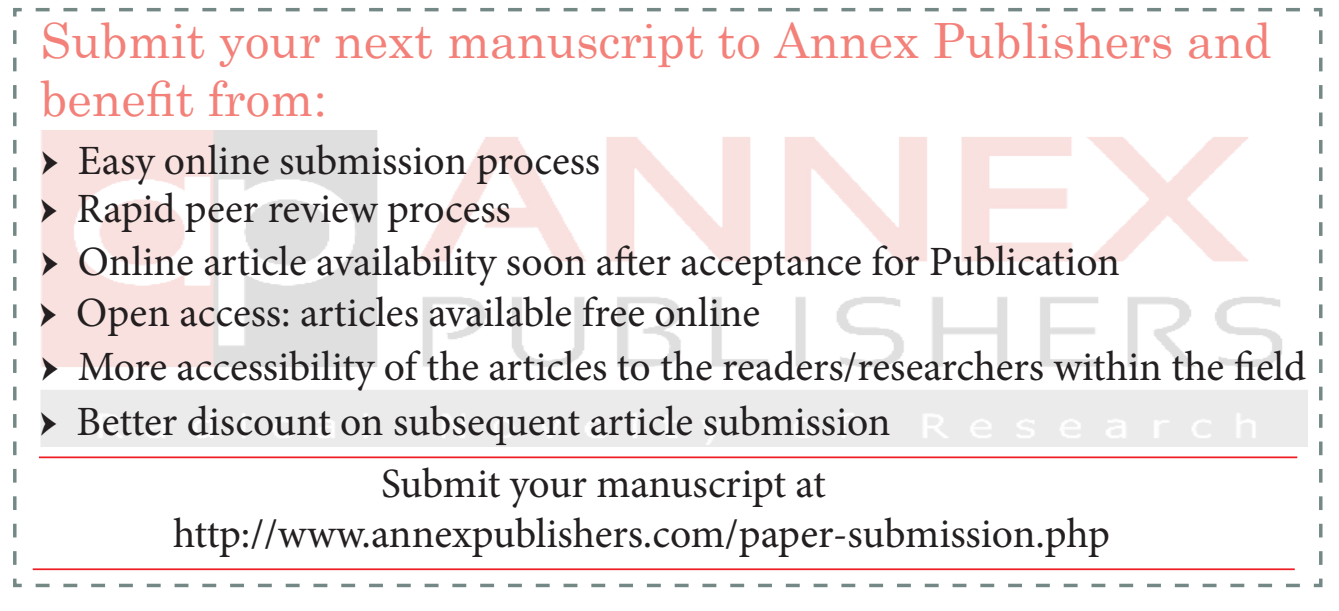

